\title{
Transplantation of the heart after circulatory death of the donor: time for a change in law?
}

\section{"the dead \\ donor rule,}

which would

arguably be

violated in

heart

transplantation

after

circulatory

death, needs

societal, legal

and medical

debate

followed by

revision or

abandonment"

James Tibballs

MD, MHlth\&MedLaw, FCICM

Neera Bhatia

LLB(Hons), LLM, PhD

1 Intensive Care Unit, Royal Children's Hospital, Melbourne, VIC

2 School of Law Deakin University,

Melbourne, VIC

james.tibballs@ rch.org.au

doi: 10.5694/mjal5.00295

Podcast with Associate Professor James Tibballs and Dr Neera Bhatia available at www.mja.com.au/ multimedia/podcasts ustralia has an increasing shortfall in transplantable hearts. Over the past decade, the number of all donors per million population increased from 10.0 in $2005^{1}$ to 16.1 in $2014 .^{2}$ However, the number of heart donations per million population over the same period has declined slightly from 3.8 to 3.4 , with an annual average of 3.3. ${ }^{3}$ Procurement of organs has always been conducted according to the dead donor rule - that is, after death of the donor - but this practice is being challenged.

The law defines death in all Australian jurisdictions (eg, in s 41 of the Human Tissue Act 1982 [Vic]) as either "irreversible cessation of all functions of the brain" (brain death) or as "irreversible cessation of circulation of blood in the body" (circulatory death), but it does not define irreversible or how to determine irreversibility (Box). Exceptionally, circulatory death is not defined in Western Australian legislation.

Although the procurement of organs such as livers, kidneys and lungs is permitted after either brain death or circulatory death according to Acts in all jurisdictions, the procurement of hearts has traditionally only been from brain dead donors with functioning hearts. The definition and diagnosis of brain death is not without controversy ${ }^{4,5}$ and may explain in part why more reliance is being placed on circulatory death, which reduces availability of hearts. ${ }^{6,7}$ Alternatively, organ procurement from patients after circulatory death may be perceived as more realisable than after brain death. Indeed, circulatory death as the source of solid organs has increased from $10 \%$ of 204 donors in 2005 to $28 \%$ of 378 donors in 2014. ${ }^{1,2}$ More total organs have been procured (from 726 to 1193) but the number of hearts has increased only slightly from 72 of 204 donors $(35 \%)$ to 79 of 378 donors $(21 \%)$ over the same period. ${ }^{1,2}$ Only 39 hearts were procured from 189 donors $(21 \%)$ during the first 6 months of $2015 .{ }^{8}$

\section{Organ donation and procurement after circulatory death}

In the practice of organ donation after circulatory death (DCD), life-sustaining treatment such as mechanical ventilation is commonly withdrawn because of a devastating neurological injury that has not progressed to brain death. The withdrawal of treatment from the donor is staged to facilitate organ transplantation to recipients. The procurement of organs is specified in the Australian national DCD protocol published by the Organ and Tissue Authority ${ }^{9}$ and enacted through the DonateLife network. It is not declared why the heart is

\section{Summary}

- Australia has a shortfall in donated hearts for transplantation.

- Hearts are usually procured from brain dead donors, but procurement from circulatory dead donors is a potential additional source.

- However, heart transplantation after circulatory death of the donor may not conform to the dead donor rule.

- An amendment in law is required to permit heart procurement for transplantation after circulatory death.

not included in the protocol's list of organs that may be procured.

Expeditious organ procurement may be commenced after death has occurred - defined in Australia as 2-5 minutes after cessation of the donor's circulation, ${ }^{9}$ and after 2 minutes in United States. ${ }^{10}$ The donor's arrested heart has not usually been procured. However, to increase the availability of hearts, routine procurement after circulatory death is proposed but not yet sanctioned in the current national DCD protocol..$^{9}$ It is probable that the protocol is under review given that the Organ and Tissue Authority lauded St Vincent's Hospital in Sydney, where two adults were transplanted with hearts procured after circulatory death in 2014. ${ }^{11}$ In those cases, the donor hearts were reanimated and kept beating and warm inside a container (ex-vivo Organ Care System, TransMedics) pending transplantation. ${ }^{12}$

This practice poses ethical, ${ }_{13}^{13}$ legal and medical problems. Foremost of the medical difficulties is the poor condition of the procured heart after it has ceased to circulate blood in the donor. However, the heart can be resuscitated with the aid of extracorporeal techniques, as was performed for the two adult recipients at St Vincent's Hospital. ${ }^{11,12}$

Heart transplantations after cardiac death have been performed in three infants in North America ${ }^{14}$ but were followed by consternation and a medical call for a moratorium on all organ procurement after cardiac death and the accusation that doctors and hospitals were biased towards organ procurement. ${ }^{15}$ The basis for the opposition was that the infants may not have been dead and possibly were conscious at the time of organ procurement. Of the three infants, one was declared dead 3 minutes after cessation of cardiocirculatory function before the process of organ procurement was initiated, and two were declared dead after 75 seconds. ${ }^{14}$ 


\begin{tabular}{lll}
\multicolumn{2}{l}{$\begin{array}{l}\text { Australian statute law governing procurement of } \\
\text { organs for transplantation }\end{array}$} \\
Jurisdiction & Act & Provision \\
\hline NSW & Human Tissue Act 1983 & s 33 \\
Qld & $\begin{array}{l}\text { Transplantation and } \\
\text { Anatomy Act 1979 }\end{array}$ & s 45(1) \\
SA & Transplantation and & \\
& Anatomy Act 7983 & s 24(2) \\
& Death (Definition) Act 1983 & s 2 \\
Tas & Human Tissue Act 1985 & s 27A \\
Vic & Human Tissue Act 1982 & s 41 \\
WA & Human Tissue and & s 24(2) \\
& Transplant Act 1982* & \\
ACT & Transplantation and & s 45 \\
& Anatomy Act 1978 & \\
NT & Transplantation and & s 23 \\
& Anatomy Act 2014 & \\
\hline
\end{tabular}

* Note: circulatory death is not defined in Western Australian legislation.

\section{Medical interpretation of the legal definition of death}

The source of the problem of heart transplantation after circulatory death is the medical interpretation of the legal definition of circulatory death. From a medical point of view, in other contexts, death is not necessarily defined by cessation of the circulation, unless it is of sufficient duration to result in brain death. It is not rare, for example, to be able to resuscitate a victim from a short duration cardiac arrest with complete neurological recovery or to sustain the circulation of a patient for lengthy periods by an extracorporeal circulation with subsequent intrinsic cardiac recovery.

The fact that a transplanted heart can function and sustain life in a recipient must mean that the circulation of the donor is never ceased irreversibly and therefore that the donor of the heart is never dead until his or her heart is removed.

The question is thus posed - how is it possible to procure the heart of a donor under the premise of circulatory death and yet expect it to sustain life in a recipient? Put differently, should the procurement of the heart be a criminal offence in such cases, because its procurement is the cause of death of the donor?

A possible argument to justify heart procurement for transplantation after circulatory death is that legal irreversible cessation of the circulation may be interpreted medically as "will not be resuscitated" rather than "cannot be resuscitated". However, that interpretation does not appear to be open to the medical profession. From a legal point of view, the meaning of legislation is governed by statute law. In the jurisdiction considered here, it is the Interpretation of Legislation Act 1984 (Vic) and
Acts Interpretation Act 1901 (Cwlth) that apply, but these are not helpful in defining "irreversible".

If a word or phrase is not defined in an Act, resort is made to common law interpretations, which may be described as literal or purposive. The literal interpretation of legislation was defined by Justice Higgins in the High Court of Australia as:

The fundamental rule of interpretation, to which all others are subordinate, is that a statute is to be expounded according to the intent of the Parliament that made it; and that intention has to be found by an examination of the language used in the statute as a whole. The question is, what does the language mean; and when we find what the language means, in its ordinary and natural sense, it is our duty to obey that meaning, even if we think the result would be inconvenient or impolitic or improbable. ${ }^{16}$

The literal approach may be too restrictive if a word or phrase has more than one meaning. In such instances, legal resort is made to a reputable dictionary - in Australia, usually the Macquarie Dictionary. Since that dictionary defines "irreversible" as "not reversible; that cannot be reversed", a legal and hence medical interpretation of irreversible cannot logically be "will not be resuscitated". Doctors cannot simply redefine the meaning of words in legislation to suit their practice.

Notwithstanding that the natural and ordinary meanings of words are the starting points in interpreting Acts, ${ }^{17}$ a purposive interpretation may be considered when a literal approach produces ambiguity or inconsistency (Acts Interpretation Act, s 15AA). Such an interpretation would be one that best achieves the purpose or object of the Act, whether expressly stated or derived from the content of the Act.

In Victoria, the stated aim of the Human Tissue Act is to make provision for removal of human tissue for transplantation and, among other aims, to provide a definition of death. The purpose of defining death is not declared but s 26 of the Act allows a designated officer and medical officers to remove tissue for transplantation only when the proposed organ donor has fulfilled the definition of death under 541 . In other words, a purpose of the Act is to prevent tissue and organ procurement from a donor who is not dead. Thus, heart procurement for transplantation under the practice of DCD is not possible under either a literal or purposive interpretation of the Act.

A similar problem with the interpretation of legislation has occurred in the United States, where death is defined in the Uniform Determination of Death Act 1982, on which Australian legislation has been modelled. The US Act also defines circulatory death as "irreversible cessation of circulatory and respiratory functions". In a purposive approach, Bernat ${ }^{18}$ has proposed that as doctors diagnose death by permanent cessation of circulatory and respiratory functions, this satisfies the requirements of death statutes and does not violate the dead donor rule. Bernat also proposes that "permanence is a perfect surrogate indicator for irreversibility" and thus permits 
heart donation after DCD. This argument is similarly not sustainable. The Macquarie Dictionary defines "permanent" as "lasting or intended to last indefinitely; remaining unchanged; not temporary; enduring; abiding". Clearly, a heart that has ceased functioning in a donor and functions later in a recipient has not ceased functioning irreversibly or permanently. Moreover, permanent cessation of the circulation is not the legal definition of death, and the concept, wrong that it is, is similarly not available to doctors to justify heart transplantation after circulatory death.

Another putative justification for heart procurement after DCD is that, whereas the heart may have stopped irreversibly in the donor's body, it is able to function in that of the recipient. This is also a spurious argument, because the only reason that the heart stops in the donor is the elective, and hence reversible, withdrawal of lifesustaining treatment such as mechanical ventilation. The heart had obviously been functioning well in the donor's body before its procurement.

\section{Possible solution}

This potential problem of heart procurement being the cause of the donor's death arises because death has been mistakenly defined in the legal sense as cessation of the circulation, without any reference to brain function. A possible alternative would be to retain the present definition of brain death as irreversible cessation of all function of the brain, but to omit the requirement for irreversibility in the definition of circulatory death and to redefine it as cessation of circulatory function with cessation of higher brain function. Under this proposition for the redefinition of circulatory death for the purpose of transplantation, procurement of a heart for the purpose of its transplantation could proceed without legal risk and without risk of retained consciousness of the donor.

\section{Conclusion}

Organ transplantation is ethical whether after brain death or circulatory death, and it is proper to maximise organ procurement, but only as permitted by law. We have shown that heart transplantation after DCD does not conform to present statute law. When the way forward is not clear in a medicolegal conundrum such as this one, legislation needs to be refined. Otherwise, as some legal academics have argued, ${ }^{19}$ procurement of a heart after cardiac death for transplantation under present legislation does not conform to the dead donor rule. This may be a potential criminal offence, an accusation that may need to be made in order to encourage law reform. Alternatively, the dead donor rule, which would arguably be violated in heart transplantation after circulatory death, needs societal, legal and medical debate followed by revision or abandonment. ${ }^{13}$ Otherwise, Australia's improving organ donor program is at risk of adverse publicity and damage if doctors, hospitals and our organ procurement agencies are perceived as procuring organs from patients not legally dead.

Competing interests: No relevant disclosures.

Provenance: Not commissioned; externally peer reviewed.

(C) 2015 AMPCo Pty Ltd. Produced with Elsevier B.V. All rights reserved.

References are available online at www.mja.com.au. 
1 Australia and New Zealand Organ Donor Registry. www. anzdata.org.au/anzod/updates/anzod2005summary.pdf (accessed Jul 2015).

2 Australia and New Zealand Organ Donor Registry. Monthly report on deceased organ donation in Australia. December 2014. www.anzdata.org.au/anzod/updates/anzod2014 summary.pdf (accessed Jul 2015).

3 Australian and New Zealand Organ Donor Registry. 2014 annual report. http://www.anzdata.org.au/anzod/vl/AR-2014. html (accessed Jul 2015).

4 Tibballs J. The non-compliance of clinical guidelines for organ donation with Australian statute law. J Law Med 2008; 16: 335-355.

5 Tibballs J. A critique of the apneic oxygenation test for the diagnosis of "brain death". Pediatr Crit Care Med 2010; 11 : 475-478.

6 Moers C, Leuvenik HGD, Ploeg RJ. Donation after cardiac death: evaluation of revisiting an important donor source. Nephrol Dial Transplant 2010; 25: 666-673.

7 de Vries EE, Snoeijis MG, van Heurn E. Kidney donation from children after cardiac death. Crit Care Med 2010; 38: 249-253.

8 Australia and New Zealand Organ Donor Registry. Monthly report on deceased organ donation in Australia. June 2015. www.anzdata.org.au/anzod/updates/ANZOD2015summary.pdf (accessed Jul 2015).

9 Australian Government Organ and Tissue Authority. National protocol for donation and cardiac death. http://www. donatelife.gov.au/national-protocol-donation-and-cardiacdeath (accessed Jun 2015).

10 Gries CJ, White DB, Truog RD, et al. Ethical and policy considerations in organ donation after circulatory determination of death. Am J Respir Crit Care Med 2013; 188: 103-109.

1 Australian Government Organ and Tissue Authority. OTA congratulates St Vincent's Hospital Sydney on Australia's first donation after circulatory death heart transplant. 24 Oct 2014. http://www.donatelife.gov.au/ota-congratulates-stvincent\%E2\%80\%99s-hospital-sydney-australia\%E2\%80\% 99s-first-donation-after-circulatory-death (accessed Aug 2015).

12 St Vincent's Hospital Sydney. St Vincent's Hospital Sydney, Australia transplants first circulatory death human heart [media release]. 24 Oct 2014. http://www.donatelife.gov.au/ sites/default/files/St\%20Vincent's\%20media\%20release.pdf (accessed Aug 2015).

13 Potts M, Byrne PA, Evans DW. Infant heart transplantation after cardiac death: ethical and legal problems. J Clin Ethics 2010; 21: 224-248.

14 Boucek MM, Mashburn C, Dunn SM, et al. Pediatric heart transplantation after declaration of cardiocirculatory death. $\mathrm{N}$ Engl J Med 2008; 359: 709-714.

15 Carcillo JA, Orr R, Bell M, et al. A call for full public disclosure and moratorium on donation after cardiac death in children. Pediatr Crit Care Med 2010; 11: 641-643.

16 Amalgamated Society of Engineers v Adelaide Steamship Co Ltd (1920) 28 CLR 129.

17 Reid v Reid (1979) 1 NZLR 572.

18 Bernat JL. How the distinction between "irreversible" and "permanent" illuminates circulatory-respiratory death determination. J Med Philos 2010; 35: 242-255.

19 Kerridge I, Lowe M, Stewart C. Ethics and law for the health professions. 4th ed. Sydney: Federation Press, 2013. 